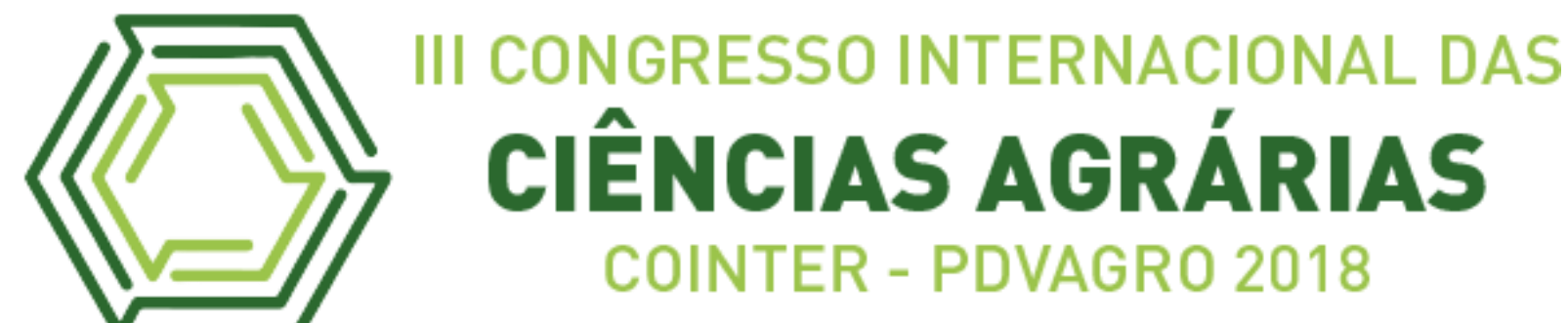

\title{
ELABORAÇÃO E AVALIAÇÃO DAS CARACTERÍSTICAS FÍSICO-QUÍMICAS DE SORVETE A PARTIR DE DOCE DE CAJU ADICIONADO DE CALDA DE RAPADURA
}

\section{PREPARATION AND EVALUATION OF THE PHYSICO-CHEMICAL CHARACTERISTICS OF ICE CREAM OF CAJU ADDED OF "RAPADURA"}

\author{
Apresentação: Pôster \\ Rosicláudia Gonçalves Ribeiro ${ }^{1}$; Clemilson Elpídio da Silva ${ }^{2}$; Cristiane Ayala de Oliveira ${ }^{3}$ \\ DOI: https://doi.org/10.31692/2526-7701.IIICOINTERPDVAGRO.2018.00459
}

\section{Introdução}

Considera-se sorvete uma dispersão coloidal, que apresenta um colóide do tipo sólido/gás, onde a fase dispersante é o sólido (gelo) e a fase dispersa é o gás (ar). Quando o sorvete tem em sua base o leite, este define-se como uma aerada dispersão de cristais de gelo e gorduras em uma solução concentrada de hidrocolóides, açúcar, proteínas e gordura. Sua composição varia conforme a região onde é elaborado, fabricante e preferências regionais.

O sorvete é um alimento que possui um alto valor nutritivo, apresenta-se como uma ótima fonte de energia e vitaminas sendo indicado para o consumo em diversas fases da vida.

Atualmente as indústrias de alimentos visando um enfrentamento a sazonalidade e os aumentos nas vendas de seus produtos têm buscado por diversificar as suas formulações, atrelado a isso, o aproveitamento de produtos da indústria de frutas visando a agregação de valor é uma condição presente. Neste caso o pedúnculo do caju é uma alternativa interessante, para a agregação de valor, aproveitamento e geração de renda. Já a utilização da rapadura, um produto tipicamente brasileiro, surge como um toque "regional" a formulação.

Diante do exposto e considerando a necessidade de aproveitamento do pedúnculo de caju, reduzindo assim os desperdícios, o objetivo deste trabalho foi elaborar uma formulação

\footnotetext{
${ }^{1}$ Acadêmica do Curso Superior de Tecnologia em Alimentos, Instituto Federal de Educação, Ciência e Tecnologia do Sertão Pernambucano - Campus Salgueiro, E-mail: rosy_claudia@outlook.com

${ }^{2}$ Acadêmica do Curso Superior de Tecnologia em Alimentos, Instituto Federal de Educação, Ciência e Tecnologia do Sertão Pernambucano - Campus Salgueiro, E-mail: clemilsonelpidio@gmail.com

${ }^{3}$ Doutora em Ciência dos Alimentos, Docente do Curso Superior de Tecnologia em Alimentos, Instituto Federal de Educação, Ciência e Tecnologia do Sertão Pernambucano - Campus Salgueiro, e-mail: cristiane.ayala@ifsertao-pe.edu.br
} 
de sorvete a partir de doce de caju em calda, adicionado de calda de rapadura e avaliar suas características físico-químicas.

\section{Fundamentação Teórica}

O cajueiro (Anacardium occidentale L.) é uma planta que possui um grande potencial econômico, pois dele se obtém um conjunto de produtos, dentre os quais o de maior interesse é a castanha. A produção de caju, no Brasil, está concentrada no Nordeste. Nesta região, a agroindústria do caju produz anualmente, cerca de 200 mil toneladas de castanhas e 2 milhões de toneladas de pedúnculo. A utilização industrial do pedúnculo de caju ainda representa uma fração mínima da produção total e se restringem basicamente à produção de sucos, refrigerantes, polpa e doces (LOPES NETO, 1997; SILVA, 1998; OLIVEIRA \& ANDRADE, 2002).

Em virtude da diversidade e riqueza na composição química da castanha e do pseudofruto (pedúnculo), o caju apresenta um elevado potencial para a elaboração de diferentes produtos alimentícios (LIMA et al., 2004).

Contudo, apesar da potencialidade do pedúnculo como matéria-prima para diversos produtos, cerca de $90 \%$ da sua produção é descartada todos os anos, em função da sua alta perecibilidade e pelo fato do principal negócio do caju ser a comercialização da castanha (PAIVA et al., 2000). Segundo Pertinari \& Tarsitano (2002) e Lima et al. (2004), além dos produtos já disponíveis comercialmente, existem diversas possibilidades de aproveitamento do pedúnculo de caju em produtos que podem atingir níveis de qualidade compatíveis com as exigências dos mercados consumidores.

A resolução $\mathrm{n}^{\circ}$ 12, de 1978 da Comissão Nacional de Normas e Padrões para Alimentos (CNNPA), do Ministério da Saúde, define rapadura como "o produto sólido obtido pela concentração a quente do caldo de cana (Saccharum officinarum)". O produto é elaborado com matéria-prima não fermentada, isenta de matéria terrosa, parasitas e detritos animais ou vegetais. Não é permitida a adição de essências, corantes naturais ou artificiais, conservadores e edulcorantes. Suas características sensoriais são: aspecto de massa dura, cor castanha, variando de claro a escuro, com cheiro e sabor próprios e gosto doce (BRASIL, 1978). Segundo a Resolução RDC n ${ }^{\circ}$ 266, de 22 de setembro de 2005, da Agência Nacional de Vigilância Sanitária (ANVISA), sorvete ou gelado comestível é um produto congelado obtido a partir de uma emulsão de gorduras e proteínas ou de uma mistura de água e açúcares. 
Pode ser adicionado de outros ingredientes desde que não descaracterizem o produto (BRASIL, 2005).

\section{Metodologia}

O experimento foi desenvolvido no Laboratório de Tecnologia dos Produtos de Origem Animal da Unidade Acadêmica de Tecnologia em Alimentos (UATA) do Instituto Federal de Educação, Ciência e Tecnologia do Sertão Pernambucano campus Salgueiro, PE. Para a elaboração do produto utilizou-se leite pasteurizado como matéria-prima e os demais ingredientes: sacarose (açúcar refinado), creme de leite (30\% de gordura), leite em pó integral, emulsificante (Emustab) e liga neutra (Duas Rodas). O produto foi elaborado conforme o fluxograma a seguir na figura 01.

Figura 1: Fluxograma de elaboração do sorvete

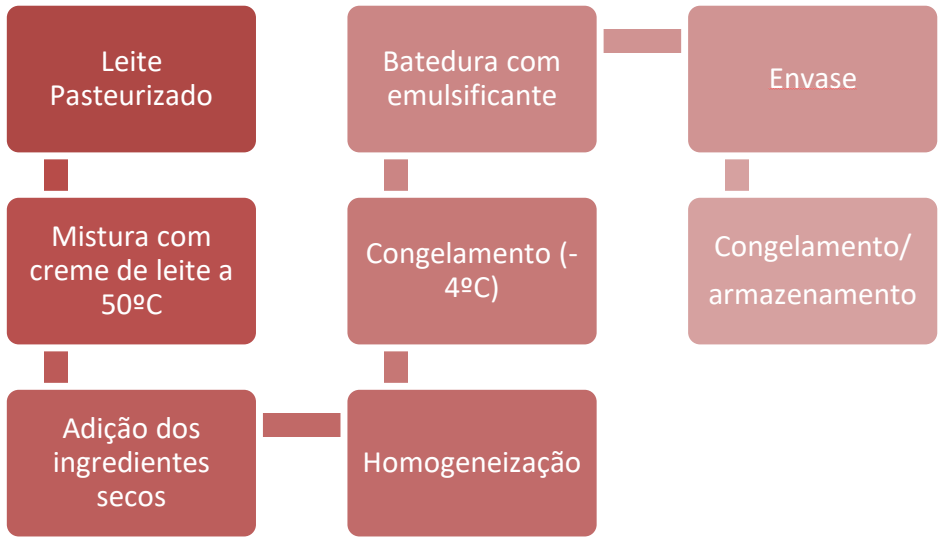

Fonte: os próprios autores

As análises realizadas no produto elaborado foram: (1) Acidez Titulável - pelo método titulométrico com solução de $\mathrm{NaOH} 0,1 \mathrm{~N}$ até $\mathrm{pH} 8,3$ e o resultado expresso \% de ácido lático; (2) pH - através da medida direta em potenciômetro; (3) Umidade - procedida à temperatura de $105^{\circ} \mathrm{C}$, em estufa; (4) Cinzas, através do método de incineração em forno mufla a $550^{\circ} \mathrm{C}$; (5) Açúcares redutores em glicose: foram determinados pela técnica da titulometria de fehling em aquecimento; (6) Açúcares não redutores em sacarose: foram determinados pelo método baseado na multiplicação da diferença entre as porcentagens de açúcares totais e açúcares redutores com o fator 0,95; (7) Açúcares totais em glicose: foi utilizada a técnica da titulometria com solução de fehling com aquecimento. Todas essas análises foram realizadas conforme a metodologia preconizada em IAL (2008). (8) Cor 
objetiva: a avaliação objetiva da cor final dos bolos foi conduzida com o uso de um calorímetro. Para o cálculo dos índices de cor, foi estabelecido o iluminante C, o ângulo de $10^{\circ}$ para o observador e o sistema de cor CIELAB. As amostras de sorvete oram dispostas em uma placa de Petri de $15 \mathrm{~mm}$ de altura até ter sido preenchida por completo e os índices de cor $\mathrm{L}^{*}, \mathrm{a}^{*} \mathrm{e} \mathrm{b}^{*}$ foram obtidos considerando-se o valor médio de seis leituras realizadas em diferentes pontos da superfície. Os dados foram computados avaliando-se a média e o desvio padrão para cada variável estudada, através do pacote Excel versão 2013 (Microsoft Office 2013).

\section{Resultados e Discussões}

Os resultados obtidos das análises físico-químicas de sorvete a partir de doce de caju em calda, adicionado de calda de rapadura encontram-se na Tabela 1.

Em relação ao parâmetro umidade obteve-se um valor de 51,63\%. Em comparação com os dados de outros pesquisadores demonstram concordância, visto que os valores obtidos por Bery et al. (2014) foi de 54,06 e 54,08\% em seu sorvete de chocolate submetido ao congelamento rápido em ultra freezer $\left(\mathrm{a}-80^{\circ} \mathrm{C}\right)$ e lento em freezer convencional $\left(\mathrm{a}-18^{\circ} \mathrm{C}\right)$, respectivamente. No que se diz respeito ao teor de cinzas, para o sorvete a partir de doce de caju em calda, adicionado de calda de rapadura foi encontrados $0,60 \%$ para resíduo mineral fixo. Marques; Antunes e Gama, (2017), encontraram 0,67\% para um sorvete de chocolate com potencial funcional. Fonseca et al. (2010) no estudo de sorvetes tipo "soft" comercializados em Lavras - MG, obtiveram $0,61 \%$ de cinzas nas amostras analisadas do estabelecimento 1 . Valores entre $0,56 \%$ para sorvete de mandacaru utilizando leite e $0,91 \%$ adicionado de soro de leite foram encontrados por Silva et al. (2016).

Tabela 1 - Resultados obtidos das análises físico-químicas do sorvete

\begin{tabular}{|c|c|}
\hline Parâmetro analisado & Média \\
\hline Umidade (\%) & 51,63 \\
\hline Cinzas $(\%)$ & 0,60 \\
\hline $\mathrm{pH}$ & 6,04 \\
\hline Acidez Total Titulável (\%) & 0,27 \\
\hline Sólidos Solúveis Totais $\left({ }^{\circ} \mathrm{Brix}\right)$ & 33 \\
\hline Açúcares Redutores (\%) & 7,05 \\
\hline Açúcares Totais (\%) & 6,78 \\
\hline
\end{tabular}




\begin{tabular}{lc}
\hline Açúcares Não Redutores (\%) & 0,27 \\
Luminosidade (L*) & 78,92 \\
$\mathrm{a}^{*}$ & 5,30 \\
$\mathrm{~b}^{*}$ & 26,7 \\
\hline
\end{tabular}

A análise do $\mathrm{pH}$ permitiu inferir característica levemente ácida ao produto $(6,04)$, próxima à neutralidade. $\mathrm{O}$ conteúdo da acidez titulável do sorvete apresentou valor médio igual a $0,27 \%$ de acidez total titulável. Os resultados encontrados são semelhantes aos reportados por Silva et al. (2016), que relataram em suas análises valores de 6,06 para pH e 0,32\% para acidez total titulável em sorvete de mandacaru utilizando leite.

Segundo Correia (2008), o pH e acidez titulável dos sorvetes são parâmetros influenciados pelo sabor empregado na formulação, podendo variar de acordo com o tipo de ingrediente utilizado, entre outras variáveis. Esses valores mais elevados são devido às várias fontes de açúcar adicionadas, como a sacarose, glicose, frutose e galactose presentes na rapadura e também devido ao leite. Conforme Perrone et al. (2011), um elevado teor de Brix pode influenciar na aceitação do produto, pois está diretamente relacionado com o sabor. De acordo com Soler; Veiga (2001), os sólidos são desejados, pois atuam melhorando a textura e a cremosidade do produto elaborado.

\section{Conclusões}

Pode-se concluir que a elaboração de sorvete a partir de doce de caju em calda, adicionado de calda de rapadura pode ser uma alternativa viável para o aproveitamento do pedúnculo de caju, produzindo-se assim um produto com características regional e potencial econômico além de reduzir os desperdícios.

\section{Referências}

BERY, C. C. de S.; VIEIRA, A. C. A.; GUALBERTO, N. C.; CASTRO, A. A. de; SILVA, G. F. da; CONCEIÇÃO, A. M. da; SANTOS, D. M. da C.;. Aceitação sensorial e caracterização físicoquímica de sorvete sabor chocolate submetida ao congelamento rápido $\left(-80^{\circ} \mathrm{C}\right)$ e lento $\left(-18^{\circ} \mathrm{C}\right)$. In: XX Congresso Brasileiro de Engenharia Química, Florianópolis, 2014.

BRASIL. Resolução n⿳ 12, de 1978. Comissão Nacional de Normas e Padrões para Alimentos (CNNPA), do Ministério da Saúde. Fixa os padrões de identidade e qualidade para os alimentos (e bebidas) constantes desta Resolução. Disponível em: <http://www.anvisa.gov.br/anvisalegis/resol/12_78_melaco.htm>. Acesso em: 08/set.2017. 
BRASIL. Ministério da Saúde. Resolução n. ${ }^{\circ}$ 266, de 22 de setembro de 2005. Regulamento técnico para gelados comestíveis e preparados para gelados comestíveis. Diário Oficial [da] República Federativa do Brasil, Brasília, 23 set. 2005.

CORREIA, R. T. P.; MAGAlHÃES, M. M. A.; PEDRINI, M. R. S.; CRUZ, V. F.; CLEMENTINO, T. Sorvetes elaborados com leite caprino e bovino: Composição química e propriedades de derretimento. Rev. Ciên. Agron., Fortaleza, v. 39, n. 02, p. 251-256, Abr.- Jun., 2008.

FONSECA, R. L.; RIBEIRO, O. A. S. ; Marcel Gomes Paixão ; PINTO, S. M. . Avaliação Físicoquímica e análise de peroxidase, fosfatase e redutase em sorvetes tipo "soft" comercializados em Lavras - MG. In: XIX Congresso de Pós Graduação da UFLA, 2010, Lavras. XIX Congresso de Pós Graduação da UFLA, 2010.

LIMA, A. C.; GARCÍA, N. H. P.; LIMA, J. R.. Obtenção e caracterização dos principais produtos do caju. Boletim do Centro de Pesquisa e Processamento de Alimentos. Curitiba, n.1, v.22, p.133-144, 2004.

LOPES NETO, A. Agroindústria do caju. Fortaleza: INPLANCE, 1997.

MARQUES, L. C. O. A. ; ANTUNES, J. A. P. ; GAMA, L.L.A. . Desenvolvimento de um sorvete de chocolate com potencial funcional: caracterização físico-química e microbiológica. ESCIENTIA, v. 10, p. 18-30, 2017.

OLIVEIRA, V. H. D.; ANDRADE, A. P. S. Produção integrada do caju. Abrindo portas para a qualidade. Disponível em: <http://www.cnpat.embrapa.br/pif/artigos/agroanalyse/index.html>. Acesso em: 10 nov. 2017.

PAIVA, F. F. A.; GARRUTI, D. S.; SILVA NETO, R. M. Aproveitamento industrial do caju. Fortaleza: Embrapa Agroindústria Tropical: Sebrae-CE, 2000. 88p. (Embrapa Agroindústria Tropical. Documentos, 38).

PERRONE, I. T. et al. Influência de diferentes espessantes nas características sensoriais do doce de leite para confeitaria. Revista do Instituto de Laticínios Cândido Tostes, v. 66, n. 379, p. 45-50, 2011.

PETINARI, R. A.; TARSITANO, M. A. A. Comercialização de caju in natura na Região Noroeste do Estado de São Paulo.

SILVA ; REIS, C. G. ; ALVES ; OLIVEIRA. Caracterização físico-química e sensorial de gelado comestível elaborado com polpa do fruto de mandacaru adicionado de soro de leite. In: I Congresso Internacional das Ciências Agrárias - I COINTER-PDVAgro, 2016, Vitória de Santo Antão - PE. Anais, 2016.

SILVA, V. V. da. (Org.). Caju: o produtor pergunta, a Embrapa responde. Brasília, DF: EmbrapaSPI; Fortaleza: Embrapa-CNPAT, 1998.

SOLER, M. P.; VEIGA, P. G. Sorvetes. Campinas: ITAL; CIAL, 2001. 68 p. (Especial, 1). 